\title{
Transforming Body, Emerging Utterance: Technique Acquisition at a Puppet Theater
}

\author{
Haruka Okui, Post-Doctoral Researcher, Paris Descartes University, France \\ Email: harukaokui11@gmail.com
}

\section{Abstract}

This paper describes the moment when a new body technique is acquired, using a case study in which three puppeteers manipulate a single puppet together. Although phenomenology assumes that the world is always "already there" before reflection begins, we can still ask how a sequence of movements is acquired. Struggling to learn puppet choreography in a training session, the learner's body encounters difficulties because it cannot easily imitate the proper movements. At the same time, the puppet master cannot easily explain those movements because he or she is so familiar with them. The communication between instructor and learner requires a kind of reflection that helps the learner transform and attain competency; this reflection is different from a dualistic disembodied form of thinking that uses abstract representation. The focus is on the precise coordination of gestures and onomatopoeic utterances that emerge through improvisation in the learner's trial movements. It is not just "a process of thinking," but an experience that evokes "a synchronizing change of my own existence, a transformation of my being" (Merleau-Ponty, 1962, p. 213), through which the puppeteer facilitates his or her own body's comprehension of new movements. Using puppetry as an example not only illuminates the phenomenon of learning a bodily skill, but also reveals the dynamics of our bodies, which can enliven our conversation, engender our transformation, and realize our being-in-the-world.

\section{Introduction}

After their daily performance, the performers at the Awaji puppet theater spend their time backstage in various ways. On one specific day, two puppeteers watch the video of an old performance, as a reference for future shows. They are attracted not only by the puppets' actions onscreen, but also by the stage installations, especially the thickly forested mountain backdrop and the configuration of a half-scale miniature house. Another puppeteer, sitting on the floor, sews a woman puppet's clothes by hand. He hems a piece of bright red cloth to fit the puppet's body - about one meter long. Behind them, three puppeteers are standing onstage with a puppet, which will play an important role in the next performance. They share 
the manipulation of the puppet, dividing its movement into three parts: the head and right hand, the left hand, and the legs.

After a short discussion, they start to manipulate the puppet, as if carefully checking the details of the choreography. Another puppeteer, watching their training, approaches them. They continue the trial manipulation again and again, sometimes vocally, sometimes silently. Although the fourth person's challenging advice often makes the trio struggle, resulting in some unsynchronized motions on the part of the puppet, the puppeteers work to improve using interactive collaborations and verbal conversations. Their vocabularies are not rich - they could even be described as poor - but their conversations are enlivened with many gestures, interwoven into their verbal expressions and expressing rich significance. How do these interactions enable the puppeteers to acquire the technique to successfully manipulate the puppet and create its animated dance? What is it like to experience such a vivid transformation? What is it like to learn to manipulate a puppet?

This paper is a phenomenological investigation that seeks to comprehend the skill necessary to acquire expertise in the puppet performance arts. As Merleau-Ponty clearly demonstrates, the acquisition of a habit — whether driving a car, playing a piano, or using a walking stick - means not only adjusting one's body to an instrument, but also modifying one's very existence. The instrument being played is not an object apart from the person who is using it; instead, it becomes a part of his or her existence, allowing him or her to accomplish whatever task is at hand. We can therefore claim that this "habit expresses our power of dilating our being-in-the-world, or changing our existence by appropriating fresh instruments" (Merleau-Ponty, 1962, p. 166). In the case of puppetry, in which a puppet dances in response to the hands of puppeteers, the puppet too becomes a kind of instrument that changes the puppeteer's existence. It becomes something more than a simple instrument belonging to its own particular world.

An enormous variety of puppets exist in this world, from traditional performance puppets (such as European marionettes or Gignols, Javanese Wayang Golek, and Japanese Bunraku) to contemporary shows involving hand puppets, finger puppets, and marionettes on strings. These are performed for many different types of spectator, from children to adults. All of these puppet performances share, however, one fundamental character; in each performance, an inanimate object behaves like an animate agent (Joseph, 1920). In other words, puppetry is a type of performance in which a human actor plays the mediator who animates something inanimate. As Heinrich von Kleist says, a marionette has an advantage over human dancers because a marionette "would never be guilty of affectation" (von Kleist, 2012 , p. 5). Although puppeteers manipulate the marionette from outside the stage, it is operated by the force of gravity and the tensions of its strings. Done well, a puppet's movements follow the equation of motion; its center of gravity transfers entirely to the mechanical force, the "path taken by the soul of the dancer" (von Kleist, 2012, p. 3).

According to von Kleist, this movement seems to be a non-conscious expression, not realized by a human body, that allows spectators to believe that the marionette is alive.

But unlike the string marionette, in the case of hand or stick puppets, puppeteers manipulate their puppets from under the stage; these kinds of puppets can be affected by human actions. In the puppet performance described in this paper, a single puppet is manipulated by three puppeteers who grasp its legs, hands, and neck from behind; thus, the puppet's "center of gravity" can never conform to a perfect geometry. The puppet cannot be 
manipulated purely or affectively apart from human factors. For this reason, such puppets involve their puppeteers in a paradoxical manipulation experience. There is a famous maxim that states, "puppeteers have to let their bodies die so that the puppet can be most fully alive" (Keene, 1990). The puppeteers aim to be absent, even when standing onstage, with many wearing black robes and cowls to conceal themselves. Hence "it is futile to wonder, as certain Europeans do, if the spectator can ever forget the presence of the manipulators" (Barthes, 1982, p. 62). This sort of animation takes place in "the narrow field between a fiction and reality," according to Chikamatsu (1738), a pioneering playwright.

To comprehend the puppeteers' experiences, this paper focuses on their training sessions. This is done for two reasons. First, training sessions allow us to see their collective body technique, consisting of trained physical movement, silent communication, choreography, and synchronized collaboration. The puppeteers learn to facilitate every motion of the puppet through gestural and verbal interactions, which would normally be hidden from researchers. These interactions provide us with fruitful material that can help to illuminate their body techniques. Second, the puppeteers' training processes evoke a pedagogical reflection. Experts' lived experiences or everyday habitual actions beg philosophical investigation (Geeves, McIlwain, Sutton, \& Christensen, 2013; van den Berg, 1987). At the same time, the training shows us incapable bodies struggling to acquire a technique that do not easily succeed. How a teacher should react is a challenging pedagogical question. It is necessary to study both how bodies respond to this situation and shape the basis for discussion, and also how collective interactions create meaning and teach "plausible insights" about our bodily experiences that bring us into more direct contact with the world (Merleau-Ponty, 1964; van Manen, 1990, 2014).

\section{Skill Learning and Learning Experience}

Although phenomenology assumes that 'the world is always 'already there' before reflection begins" (Merleau-Ponty, 1962), we can still ask how a sequence of movements is acquired. During the process of transforming a bodily technique through imitation, trial, and learning, the body has not yet comprehended the meaning of a movement, and the world has not yet expressed its familiar physiognomy.

Skill acquisition is an experience of the world's transformation rather than the development of a personal competency (Dreyfus \& Dreyfus, 1986). When we start to learn a skill, we move in accordance with the advice of our instructor who decomposes the task environment into context-free features and gives rules for determining actions on the basis of these features that a beginner can recognize without previous experience (Dreyfus, 2002). With experience, however, we escape the control of representation, calculation, or rule, and our bodies begin to move by themselves. As Dreyfus observes, "he or she knows how to perform the appropriate action without calculating and comparing alternatives. What must be done, simply is done" (Dreyfus, 2002, p. 372). What the learner acquires through experience is "not represented in the mind," but "presented to the learner as a more and more finely discriminated situation" (Dreyfus, 2002, p. 373). Dreyfus's description not only deepens the acquisition process, which Merleau-Ponty mostly ignored, but also conceptualizes the entire 
non-representational process of learning, which corroborates Merleau-Ponty's critique of both idealism and empiricism (Sutton, McIlwain, Christensen, \& Geeves, 2011). Dreyfus concludes that the intention of an action (the agent's goal and conditions of satisfaction) does not have to be represented in the actor's mind. There is therefore no dualism in the expert's experience.

Dreyfus admits that the learning experience includes analysis, however, which allows the agent to reflect on the movement. He offers the example of a tennis game. Unlike an expert absorbed in the game, in learning how to swing a tennis racket, for example, one "might find oneself making an effort to keep one's eye on the ball, keep the racket perpendicular to the court, hit the ball squarely, etc." (Dreyfus, 2002, p. 378). This example indicates that the learners need to analyze their gestures and follow rules to improve their movements. If this is the case, these analytic processes "clearly contradict the phenomenological conditions for what counts as an activity of involved coping" (Dreyfus, 2002 , p. 381). If learning a skill depends on analytic composition, which could defend the dualistic position that supposes rules to govern movement, is learning then comprised of two separate experiences? Alternatively, does the proposition that the world is "already there" only apply to the actions of an expert? Can we understand the beginner's lived experience from a phenomenological perspective?

Among various phenomenological approaches to skill acquisition, bodily reflection is one of the main topics (Legrand \& Ravn, 2009; Sheets-Johnstone, 2011; Shusterman, 2008). Following this particular lead, in the present investigation, I concentrate on communication between the expert and the learner that enriches the learning experience (Smith, 2007, 2014). So, while Dreyfus's account clearly demonstrates that an instructor can transmit body technique by decomposing the situation, many teachers and students believe this advice to be insufficient, as it cannot be transmitted person-to-person, especially during acquisition (Weissensteiner, Abernethy, \& Farrow, 2009).

A training session in acquiring new bodily techniques reveals the fundamental difficulties in communication between instructor and apprentice (Andrieu, 2017). These arise from the fact that training requires communication between participants who do not share a common technique. The apprentice cannot easily imitate movements with which he is unfamiliar. The instructor who has already acquired a technique cannot return to the unable body and cannot understand why the apprentice is unable to make a movement, being already too familiar with those movements. The instructor's task of imagining what it is like to be a beginner and bringing out the student's movement is fundamentally different from performing with his or her own body. In short, an excellent performer is not necessarily an excellent teacher. That is why, viewed positively, training sessions are full of vivid challenges and attempts to communicate across the gap between the instructor and the apprentice. It is like trying to have a conversation in a new language without sufficient vocabulary. The effort and the struggle to teach and acquire bodily techniques thus provides a rich opportunity, not just to consider our own teaching and learning experiences, but also to reflect on and relive the dynamic bodily experience of transformation (Smith, 2011).

This paper is directed at understanding phenomenology through my 'fieldwork,' over the course of a five-year doctoral project. ${ }^{1}$ My research has included observing performers'

1 This project was conducted from 2010-2014 at Kyoto University. This article was supported by JSPS KAKENHI Grant Number 26780444. 
everyday training sessions, interviewing them about the experience of manipulating puppets, and evaluating stage performances. Although anthropological considerations are definitely important, this paper considers puppetry not in relation to a specific culture, but in the context of the experience of teaching and learning. Socio-anthropological explanations do not illuminate the moment when participants teach and learn new knowledge. It should also be mentioned that this paper does not promote any alternative or traditional style of learning. Instruction and education in traditional puppetry are certainly different from any school-based form of education, since most techniques are transmitted through unformulated and nonverbal communication, passed down from generation to generation, or transmitted through community participation (Lave \& Wenger, 1991). Learning, therefore, might be regarded as more than a mere increase in knowledge. The fuller experience of teaching and learning underpins those moments in which participants realize for the first time that they know a new movement or have experienced a moment of transformation (van Manen, 1991). Such moments are embedded in interactions that cannot be reduced to social or community functions; instead, they enrich ordinary life and the community to which participants belong.

\section{The Training of a Puppeteer}

The Awaji Puppet Theater is one of the oldest professional puppet troupes in Japan. ${ }^{2}$ It has experienced extinctions, adaptations, and integrations during its 400 year existence (Law, 1997). The children in this region, in the south part of Awaji islands, watch puppetry at school or the theater, even if it is a spectacle for adults. ${ }^{3}$ They commonly describe their first encounters with puppets with mixed impressions like "horrible" and "out of fashion," but also "beautiful." It could be horrible because of the non-human but humanlike objects presented in an old-fashioned style of clothing and visage. But, simultaneously, the harmonious puppet's gestures are so beautiful that it cannot be believed that it is an inanimate object. Some children, fascinated by the performances, begin learning puppetry in youth associations and can apply to professional troupes if they aspire to do so.

When it comes to puppetry techniques, it takes a novice approximately seven years to become a leg puppeteer. After mastering leg manipulation, puppeteers start learning to

2 The Bunraku is the most famous form of puppetry presented at the National Theater in Osaka. In the seventeenth century, it was one of the most popular and sophisticated urban performances conducted at the theater. Awaji is of its own origin but was later influenced by the development of Bunraku. Its puppeteers in the seventeenth century were itinerant troupes that performed their elaborate puppetry in temporary outdoor theatres in fields, travelling around larger areas of Japan, and did not have any permanent theater except a temple's ritual stage.

3 All stages are usually present for adult spectators, consisting of three types of performers: narrator, accompanist, and puppeteers. The narrator presents the characters' line and asides, as well as the plot. The accompanist uses the shamisen, whose sound resembles that of a banjo, to create rhythms, tempos, and moods that work in collaboration with the narration, each supporting the other to express the thoughts and feelings of the characters, with which the puppeteers play. The narrator and the accompanist give their performances on the right side of the stage, while the puppeteers manipulate the puppets in the center. 
manipulate their puppets' left hands, which takes a further seven years to master. Only when all other body parts have been mastered do puppeteers in training begin to manipulate the puppets' heads. Head puppeteers are responsible not only for manipulating the puppet's head and right hand, but also for directing the other two puppeteers, together making a puppet perform as the main character onstage.

About the puppet's manipulation, one puppeteer said that it is a paradoxical experience, like the plural sense of a dual personality. On the one hand, the puppeteer empathizes with the puppet in the scene in order to express efficient acting: the strong feeling of a tragic heroine or the powerful energy of an avenger. On the other hand, too much identification interferes with the performance because the puppeteer's extra gestures can be conspicuous to the spectators. Another paradox exists in the three-person-manipulation technique. Puppet manipulation affords an experience in which the puppeteer's body is not controlled by his own will. Even if there is a leader, the head puppeteer, who signals to the other two puppeteers when to start a movement, this head puppeteer has to adjust the others' tempos. Moreover, he devotes himself to enlivening the puppet, which is to say, to moving according to the puppet's body parts. It is the puppeteer's own body that adapts to the puppet, not vice versa. Thus, no single independent ego in possession of his or her own body exists onstage.

Now consider a specific troupe in charge of manipulating a specific puppet. The play in question is a war history and the puppet plays a soldier, who is trying to arrest the hero. Four puppeteers are present at all training sessions for this puppet. Three (X, Y, and Z) manipulate the puppet, while the other $(\mathrm{S})$ is the instructor. Among the puppeteers, $\mathrm{S}$ has had the longest career - almost thirty years. Head puppeteer X and left-hand puppeteer $Y$ each have had twenty-five-year-long careers, and Z, who manipulates the legs, has been a puppeteer for twenty years. In one session, they try to learn two types of choreography - known as Uchi-komi and Kojiri Roppo - in order to block one scene. These choreographies are generally listed as basic sets of movements, comprising about 20 types of actions for female puppets and 50 types for male puppets. Puppeteers never modify these actions in accordance with their own personal interpretations, but always retrace pre-defined historical actions.

We can divide the next training session into two parts. First, the puppeteers practice Uchi-komi, which the head puppeteer has proposed including in the sequence. Then $\mathrm{S}$ introduces them to Kojiri Roppo, which they try for the first time. The description of learning Kojiri Roppo is divided into the following two parts: First Difficulty, in which miscommunication provides us with an example of the confusing acquisition process, and Second Difficulty, in which an emerging utterance reveals the struggle to learn new movements.

\section{An Easy Case: Transparent Body and Body Schema}

The choreography of Uchi-komi, which X, the head puppeteer, wants to introduce, is not difficult for the trio. They perfect the movements after two or three trials. For the observer, this scene illustrates the participants' rich set of interactions and their abundant bodily 
expressions. ${ }^{4}$

X proposes to include $U c h i-k o m i$ in the scene, and the other two puppeteers agree. During practice, the master puppeteer S approaches to observe them. X asks him to correct the choreography, saying, "Is this okay?" (See Figure 1.) S demonstrates the movements himself and confirms the actions of the group, saying, "Yes, that's it." $\mathrm{X}$ continues the movement and asks again, "And then, like that?" S confirms again:

"That's it." Accepting the master's answer, the three puppeteers repeat the choreography another two times.

Let us consider the experiences of the four puppeteers. At first, although their vocabulary is not particularly rich, we can see that their bodies express abundant meaning. The spoken words (e.g., "it" and "that") are "genuine gestures" (Merleau-Ponty, 1962, p. 213) that immediately express their meanings beyond detailed verbal explanations. The most important point here is S's manner of instruction. He explains the puppet choreography by demonstrating it with his own body, as if he were the puppet. His instruction directs how the puppet should move rather than how the puppeteers should manipulate the puppet. The puppeteers and S pay

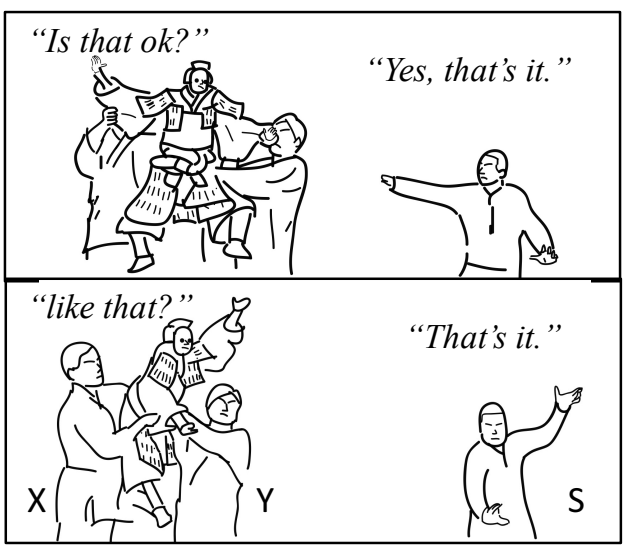

Figure 1: Confirmation no attention to the puppeteers' movements, although they must be considering how to rise, grip, and twist. Their own bodies are instead transformed directly into the puppet's body.

This session reminds us of the notion of the "body schema." Merleau-Ponty (1962), using a contemporaneous psychological interpretation, deepens the significance of this concept to include "a total awareness of my posture in the inter-sensory world, a 'form' in the sense used by Gestalt psychology" (p. 117). He also defines the body schema not as a static form that informs us of the body's position, but as a dynamic system. His description, for example, of an organist's experience, might be adaptable to the puppeteers' case. A skilled organist can play any type of organ if he or she practices for a few hours before going on stage because movement is not made up of individual units of action, but should be understood as a "system of equivalents," or "immediately given invariant whereby the different motor tasks are instantaneously transferable" (Merleau-Ponty, 1962, p. 117).

Master puppeteers in Awaji can imitate the puppet's choreography using their own bodies and reproduce their own bodily movements in the puppets to the extent that the puppet's extremities can move. They can perform just like the puppets even if it is not

\footnotetext{
${ }^{4}$ Figure 1 does not show the whole body of leg puppeteer $\mathrm{Z}$ because he manipulates the puppet's legs from behind. His right hand grasps the puppet's right leg in the second picture in Figure 1. This training session takes about one hour in total, including the two episodes discussed later. The author made this video with the puppeteers' permission. In order to clarify the moment of physical expression, this paper includes hand-drawn images created on a tablet computer using Adobe Ideas. Like the instructor puppeteer, $\mathrm{S}$, demonstrating the choreography to the other three, these figures show their rich but nontranscribable gestural significations.
} 
necessarily an obligation to learn how to move the puppet. Although puppeteers' tasks during performances are to grasp their sticks, which are connected to each part of the puppet, they live in the puppet's body through their own arms and hands beyond the end of the stick. The puppeteers' bodies merge into the puppet's body, which is directly driven by the choreography. In other words, acquisition of puppet manipulation might be an acquisition of a new body, that of the puppet, which the puppeteer moves in accordance with the puppet's body schema.

\section{First Difficulty and Miscommunication}

During training sessions, as the puppeteers strive to learn new movements, their tasks are not equally difficult. The choreography is easier for the puppeteers who move the legs and left hand, and more difficult for the puppeteer who moves the head and right hand. The next example is more complicated; the three puppeteers see the difficult Kojiri Roppo choreography for the first time. According to instructor $\mathrm{S}$, this choreography is suitable for the scene being practiced and consists of a complex motion that uses both right and left hands. Although the three puppeteers and $\mathrm{S}$ eventually succeed in learning the movements, they face a difficult task of communication. ${ }^{5}$

S explains the choreography. The three puppeteers try to follow the complex movements, but cannot do so. When $\mathrm{S}$ demonstrates the choreography using his body, puppeteers $\mathrm{Y}$ (responsible for the left hand of the puppet) and Z (legs) start to follow $\mathrm{S}$, but the puppeteer in charge of the head and right

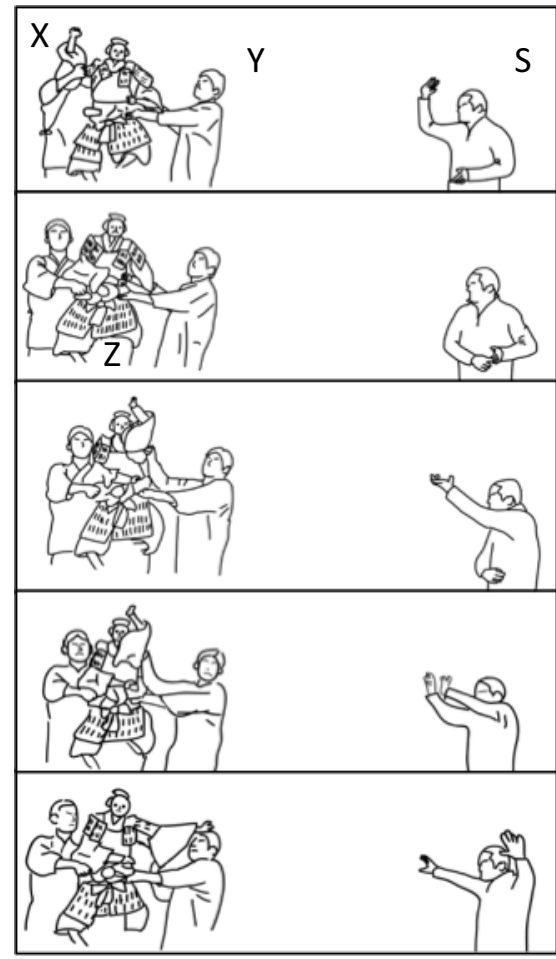

Figure 2: A part of the choreography hand, $\mathrm{X}$, cannot yet follow the movements. $\mathrm{X}$ admits that he is struggling, and $\mathrm{S}$ takes over the manipulation of the puppet's head, leading the other two. Watching S's movements, $X$ understands the choreography's flow. But X is still missing a part of the movement; when the puppet opens both arms horizontally at the same time, $\mathrm{X}$ cannot manipulate the right arm. He asks the master about this motion. S demonstrates the choreography and says, "That's it, then, like that." (See Figure 3.)

$\mathrm{X}$ still does not understand. He sets the puppet aside and starts to use his own body to enact the choreography. After a few trials and short conversations, he begins to acquire the movements. Thanks to this trial, $\mathrm{X}$ learns the choreography and can now lead the other two puppeteers, both of whom also succeed.

We can notice two types of miscommunication in the first part of this example. The first communication failure is at a more fundamental level and is caused by a gap in

${ }^{5}$ Like Figure 1, Figure 2 does not show the leg puppeteer's whole body because he manipulates the puppet's legs from behind. We can see his hands grasping the puppets' legs. 
experience between the master and the novices. Figures 2 and 3 show their conversation precisely. When $\mathrm{X}$ asks how to open the puppet's arm, $\mathrm{S}$ uses a bodily gesture that suggests a simple explanation (Figure 3). The master, who has already learned the choreography, is so familiar with it that he cannot explain it verbally. The novice does not understand his demonstration.

$\mathrm{Y}$, the puppeteer manipulating the puppet's left hand, causes the second miscommunication because he starts to move before $\mathrm{X}$ (Figure 2). Because he is concentrating so hard on his task of manipulating the left hand, he inadvertently follows S's demonstration of the choreography. This means that $\mathrm{Y}$ ignores the important rule that puppeteers must wait for a signal from the head, in this case from $\mathrm{X}$. Therefore, if $\mathrm{S}$ were to advise them, he could tell $\mathrm{Y}$ to wait for $\mathrm{X}$ to move first. No one recognizes the miscommunication between the head and the left hand right away, however, because Y's movement is correct in appearance. This is also because $\mathrm{S}$ is so familiar with the choreography that his hands move almost automatically, and so he cannot understand the importance of the coordination with the left hand puppeteer. As a result, the new temporal relationship between $\mathrm{Y}$ and $\mathrm{S}$ confused $\mathrm{X}$. This resulted in a miscommunication between $\mathrm{X}, \mathrm{Y}$, and $\mathrm{S}$, none of whom shared their confusions with the others.

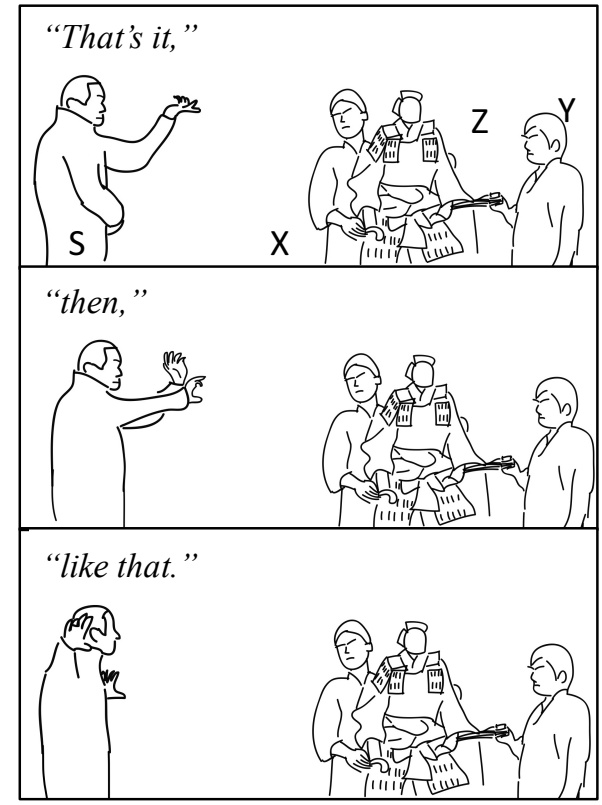

Figure 3: S's demonstration

\section{Second Difficulty and Emerging Utterance}

The second phase of this situation begins when $\mathrm{X}$ starts to comprehend the choreography through his own body. Since he cannot master the puppet choreography, he does something unexpected. To confirm the sequence of new movements, he moves through parts of the choreography by tracing them with his body, accompanying the movements with onomatopoeic utterances that emerge through improvisation in the learner's trial movements. This trial requires a precise coordination of gestures and utterances. Below are presented five sequences in order to follow X's steps in mastering the choreography.

Phase 1: $\mathrm{X}$ tries the choreography with his own body without saying a word and succeeds. S appreciates it, but $\mathrm{X}$ is not yet certain. Phase 2: He retries it with some onomatopoeic utterances, like "pam." Now he makes the same mistake as when manipulating the puppet: he forgets to open his hands. Phase 3: He tries it again with a new utterance, like "shh!" and succeeds. Phase 4: X confesses that he wants to skip the stage of opening the hand because it seems useless. Y recommends removing it, but $\mathrm{X}$ now claims that the gesture actually makes the choreography showier and is therefore indispensable. Phase 5: He practices again, using the same utterance, and succeeds. His movements become smoother. 
Tracing the new choreography with his body, he confirms its sequence and accompanies the movements with onomatopoeic utterances. Here we note his two types of reflection: bodily expression and semantic investigation. First of all, after his failure during the second phase, $\mathrm{X}$ succeeds by practicing the choreography with the onomatopoeic utterance, "shh!," as well as "pam." His focus is on the precise coordination of gestures and utterances. The new gesture suits the sound "shh!," which evokes something swishing through the air or flying horizontally. Before, when $\mathrm{X}$ practiced, no linguistic signification connected the gesture to the sound. The performers' utterances are not simply representational speech, but also expressions of the embodied self. They facilitate the body's comprehension of the new movements. This is the moment when the puppeteer's body grasps the meaning.
Phase 2: Mistake

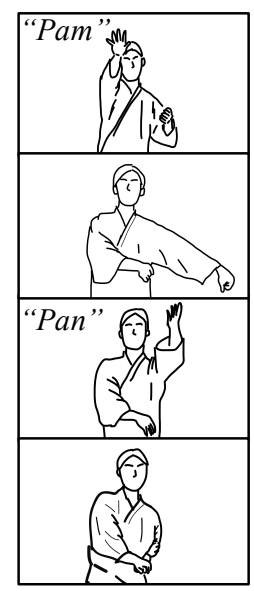

Figure 4: Emerging utterance
Phase 3: Success

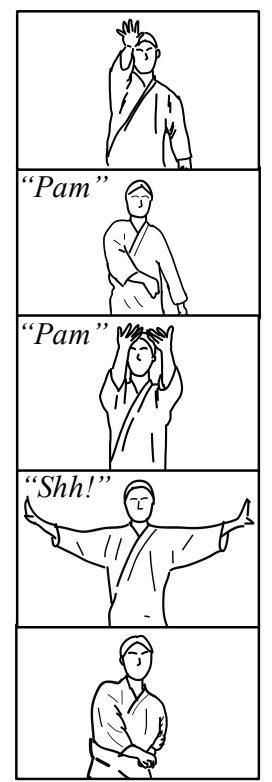

The second reflection is more semantic. $X$ interprets the meaning of the choreography; he does not want to open the puppet's hands, preferring to directly grip the sword. Although he could change the choreography to reflect his own preference, he finally accepts the original by interpreting its meaning. In his view, the opening hands make the choreography showier, confirming the importance of the movement. On the one hand, $\mathrm{X}$ seems to respect the choreography because it is formed through tradition; he argues in favor of keeping the form, even if it is incomprehensible. On the other hand, his sense that the hand's action could be made more effective is primarily conjectural. In any case, this second reflection is not necessarily the representational, mental analysis that Dreyfus passed over as idealistic. X's interpretation of the choreography is not just abstract - "open the hand"-but concrete; "it makes the puppet showy." Even if his interpretation of this traditional choreography is incorrect and nobody in fact knows its original meaning, it is helpful for bringing the soldier puppet to life in this scene. Therefore, his interpretation is embodied or situated rather than abstract or context-free.

These two processes of reflection show that thinking forms a part of movement. There is no dualism. As Merleau-Ponty points out, one does not acquire a dancing movement "by analysis" or "the formula of the movement" that reconstructs the new movement "on the basis of the ideal outline by the use of previously acquired movements" (Merleau-Ponty, 1962, p. 165). Rather, where possible, the analysis "must first have had . . the stamp of movement set upon it." (Merleau-Ponty, 1962, p. 165) Movement is not merely thinking about movement. Thought in movement is itself movement because one can think in movement (Sheets-Johnstone, 2011).

The most important point is that X's exploration has made it possible for him to acquire complex choreography. This means that it is not analysis that uncovers the "formula of the movement" but, rather, learning through embodied movement and utterance. I have focused here on two types of speech: onomatopoeic utterances (phase 3) and discussion (phase 4). We can say that this trial movement with its associated utterances is not just "a 
process of thinking." From the point of view of the student-puppeteer, it evokes "a synchronizing change of my own existence, a transformation of my being" (Merleau-Ponty, 1962, p. 213). This onomatopoeic utterance that Merleau-Ponty would call "motor grasping of a motor significance" (1962, p. 165) is crucially distinct from discussion. We might say that this onomatopoeic utterance is the body itself speaking.

\section{Conclusion}

Although it is agreed that the beginners cannot perform like experts who no longer need to reflect on or calculate his or her movements, it does not follow that this beginner needs to only connect rules with physical movements. As I have described in this paper, the learner also lives in the lifeworld of expert performance, even if it is seen, felt, and expressed differently than that of the expert. So, while it is true that there are differences between representative analysis and non-representational movement, this does not mean that the analysis must be done though disembodied representation.

Now we can reconsider the contradiction between the analysis and the movement. The first case (Uchi-komi) shows us the flexibility and unity of the human body through the work of body schemata. It depicts, on the one hand, the puppeteer who has already acquired the manipulation technique to reproduce the puppet choreography in his body as if he were it. But at the same time, this complete incorporation of the puppet's choreography evokes the fundamental gap between the master and the pupil; the master cannot explain how to manipulate the puppet (how to send a signal to the other puppeteer, how to follow the choreographic trajectory, etc.) and can only demonstrate how to be the puppet, which causes miscommunication in the second case (Kojiri Roppo, the first difficulty).

In order to bridge the gap and imitate the master's demonstration, the student X sets the puppet aside and performs the puppet's choreography with his own body (Kojiri Roppo, the second difficulty). This trial solidifies knowledge of the movement required not only by simple repetition but also through attentive understanding made up here of onomatopoeic expressions. Finally, the student can understand its semantic structure through an interpretation that helps comprehension of the choreography. Although this interpretation facilitates acquisition of the technique, we cannot identify it as the "decomposition" that Dreyfus proposes for characterizing learning. It is true that the semantic interpretation could help X understand the choreography, but this interpretation works more favorably alongside engaged trials using the body since the student has already understood part of the choreography through the motor-grasping trial in which the onomatopoeia is precedent to the semantic interpretation.

If decomposition and rules can help students' acquisition of technique, it should be under the condition that the body has already started grasping the signification of the choreographic trajectory. The reverse is not true, that is, that rules that lack motor significance cannot educe movement. The student's repeated trial is a process of lived-thinking or moving that reorganizes the unity of choreography and apprehends the emerging meaning. The problem might be that both master and pupil cannot foresee the moment when the first motor grasping arrives. Merleau-Ponty (1962) describes this moment when a new meaning is formed as happening "suddenly:" 
Sometimes a new cluster of meanings is formed; our former movements are integrated into a fresh motor entity, the first visual data into a fresh sensory entity, our natural powers suddenly come together in a richer meaning, which hitherto has been merely foreshadowed in our perceptual or practical field, and which has made itself felt in our experience by no more than a certain lack, and which by its coming suddenly reshuffles the elements of our equilibrium and fulfills our blind expectation. (p. 177, emphasis added)

Sometimes a student learns easily; at other times, he or she can only repeat the movement. The moment in which the body comprehends arrives suddenly. The moment in which "a bodily logos is at work" (Sheet-Johnstone, 2000, p. 355) is when the student experiences what the body achieved. Since the motor grasping is obscure before acquisition, puppeteers require a kind of reflection to provoke this transformation. Such reflection does not help acquisition by controlling an obedient body. Rather, the body itself thinks through the process of moving as happened with puppeteer X's onomatopoeic expression, which signifies the sudden moment of transformation. If this were a ready-made learning method, $X$ 's expression would be under his mental control and would not have any particular significance. The significance of the movement and the onomatopoeic expression are, however, in accord with each other. The verbal expression expresses the body's comprehension of the physical movement, upon which some form of representation might be constructed.

Teaching and learning Awaji puppetry is not a simple act of transferring knowledge from one person to another according to well-organized instruction. As became evident in the foregoing description, it includes tense moments that sustain a difficult drama in which the student puppeteer attempts the movements again and again until his body knows the choreography. This way of learning that requires onomatopoetic expression is, of course, but one aspect of body movement acquisition. Other domains of expertise, like dance, music, sports, or surgery, require more detailed verbal instructions that evoke more complex interactions (Hirschauer, 1991; Schiavio \& Hoffding, 2015). But the primitive verbal expression and reflection that this paper focuses on illuminates how bodies or gestures underpin technique acquisition in verbal communications. These considerations also illuminate not just learning bodily skill itself, but also the potentiality of our bodies to activate conversation and become bodily transformed in learning to live large in the world.

\section{References}

Andrieu, B. (2017). Apprendre de son corps: Une méthode émersive au CNAC. Rouen: Presses universitaires de Rouen et du Havre.

Barthes, R. (1982). Empire of signs. (R. Howard, Trans.). New York: Hill and Wang.

Chikamatsu, M. (1738/1959). Chikamatsu jōruri shū. K. Shigetomo \& K. Shuzui (Eds.), Tokyo: Iwanami Shoten. 
Dreyfus, H. L. (2002). Intelligence without representation-Merleau-Ponty's critique of mental representation: The relevance of phenomenology to scientific explanation. Phenomenology and the Cognitive Sciences, 1(4), 367-383.

Dreyfus, H. L., \& Dreyfus, S. E. (1986). Mind over machine: The power of human intuition and expertise in the era of the computer. New York, NY: Free Press.

Geeves, A., McIlwain, D. J. F., Sutton, J., \& Christensen, W. (2013). To think or not to think: The apparent paradox of expert skill in music performance. Educational Philosophy and Theory, 46(6), 674-691.

Hirschauer, S. (1991). The manufacture of bodies in surgery. Social Studies of Science, 21(2), 279-319.

Joseph, H. (1920). A book of marionettes. New York, NY: B. W. Huebsch.

Keene, D. (1990). Nō and bunraku: Two forms of Japanese theatre. New York, NY: Columbia University Press.

Lave, J., \& Wenger, E. (1991). Situated learning: Legitimate peripheral participation. Cambridge [England]; New York, NY: Cambridge University Press.

Law, J. M. (1997). Puppets of nostalgia: The life, death, and rebirth of the Japanese Awaji ningyō tradition. Princeton, NJ: Princeton University Press.

Legrand, D., \& Ravn, S. (2009). Perceiving subjectivity in bodily movement: The case of dancers. Phenomenology and the Cognitive Sciences, 8(3), 389-408.

Merleau-Ponty, M. (1962). Phenomenology of perception. (C. Smith, Trans.). London; New York, NY: Routledge \& Kegan Paul. (Original work published 1945)

Merleau-Ponty, M. (1964). Signs. (R. C. McCleary, Trans.). Evanston, IL: Northwestern University Press. (Original work published 1960)

Schiavio, A., \& Hoffding, S. (2015). Playing together without communicating?: A pre-reflective and enactive account of joint musical performance. Musicae Scientiae, $1-23$.

Sheet-Johnstone, M. (2000). Kinetic tactile-kinesthetic bodies: Ontogenetical foundations of apprenticeship learning. Human Studies, 23(4), 343-370.

Sheets-Johnstone, M. (2011). The primacy of movement. Amsterdam; Philadelphia, PA: John Benjamins Pub. 
Shusterman, R. (2008). Body consciousness: A philosophy of mindfulness and somaesthetics. New York, NY: Cambridge University Press.

Smith, S. J. (2007). The first rush of movement: A phenomenological preface to movement education. Phenomenology \& Practice, 1(1), 47-75.

Smith, S. J. (2011). Becoming horse in the duration of the moment: The trainer's challenge. Phenomenology \& Practice, 5(1), 7-26.

Smith, S. J. (2014). A pedagogy of vital contact. Journal of Dance \& Somatic Practices, 6(2), 233-246.

Sutton, J., McIlwain, D., Christensen, W., \& Geeves, A. (2011). Applying intelligence to the reflexes: Embodied skills and habits between Dreyfus and Descartes. Journal of the British Society for Phenomenology, 42(1), 78-103.

van den Berg, J. H. (1987). The human body and the significance of human movement. In J. J. Kockelmans (Ed.), Phenomenological psychology: The Dutch school (pp. 55-77). Dordrecht: Nijhoff.

van Manen, M. (1990). Researching lived experience: Human science for an action sensitive pedagogy. Albany, NY: State University of New York Press.

van Manen, M. (1991). The tact of teaching: The meaning of pedagogical thoughtfulness. Albany, NY: State University of New York Press.

van Manen, M. (2014). Phenomenology of practice: Meaning-giving methods in phenomenological research and writing. Walnut Creek, CA: Left Coast Press.

von Kleist, H. (2012). On the marionette theatre. (I. Parry, Trans.). In K. Gross (Ed.), On Dolls (pp. 1-10). London: Notting Hill Editions. (Original work published 1810)

Weissensteiner, J., Abernethy, B., \& Farrow, D. (2009). Towards the development of a conceptual model of expertise in cricket batting: A grounded theory approach. Journal of Applied Sport Psychology, 21(3), 276-292. 